\title{
Participation, academic influences and interactions: A comparison of Chinese and U.S. research universities on ResearchGate
}

\author{
Participation, influences \\ universitaires, et \\ interactions : \\ comparaison des \\ universités de recherche \\ chinois et étasuniennes \\ sur ResearchGate
}

\author{
Weiwei Yan \\ Wuhan University

\section{Yin Zhang \\ Kent State University}

\begin{abstract}
ResearchGate (RG) is an academic social networking (ASN) site that is used worldwide for scholarly communication. This study examines RG users from 21 top Chinese research universities and 61 U.S. research universities from three research activity levels to identify the differences in participation, interactions, and academic influences between their affiliated institutions on this ASN platform. The implications on scholarly communication and evaluation using altmetrics across nations are discussed.
\end{abstract}

Keywords: institutional difference, cross-country comparison, academic social networking site, user behaviour, ResearchGate

Résumé : ResearchGate (RG) est un réseau social de chercheurs utilisé dans le monde entier pour favoriser les échanges scientifiques. Cet article vise à étudier les différences dans la participation, les interactions et les influences scientifiques entre les institutions d'attaches d'utilisateurs de ce réseau issus de 21 universités de recherche chinoises et de 61 universités de recherche étasuniennes. Les répercussions sur la communication savante et les évaluations à l'aide de mesures d'impact alternatives (altmetrics) entre les pays y sont aussi abordées.

Mots clés : différences institutionnelles, comparaisons entre pays, réseaux sociaux universitaires, comportement des utilisateurs, ResearchGate 


\section{Introduction}

Academic social networking (ASN) sites have been increasingly used by scholars world-wide. The combination of rapid development in social network technologies and explosive growth in publication output has turned these sites into research-oriented platforms effective for implementing web-based academic interaction and networking, as well as presenting professional images (Xia et al. 2016). The phenomenon has driven research on the scholarly use of ASN, which previously has focused on studying research impact using metrics, including traditional metrics and newly available alternative metrics from the ASN sites (Thelwall and Kousha 2015; Yu et al. 2016), as well as how scholars accept and use the ASN sites, interacting with the platform and their peers alike (Meishar-Tal and Pieterse 2017; Lee et al. 2019). There has been a research gap in examining the use differences of ASN sites by country, especially the use differences between developed and developing countries aiming to reach the global academic research community.

This study is exploratory in nature, aiming to fill the gaps in cross-national research on ASN sites. The purpose of this study is to examine the differences in participation, interactions, and academic influences in the widely adopted ASN site, ResearchGate (RG), between Eastern and Western countries. The U.S. is the most developed country with prominent academic influence and a large number of RG members, while China was noted as a country that may be missing opportunities to use RG to maximize the academic impact (Thelwall and Kousha 2015). Therefore, this study chose users affiliated with research universities from the U.S. and China, representing both a developed, native English country and a developing, non-native English country, respectively. Specifically, this study seeks to answer the following research questions (RQs):

$R Q 1$. What are the cross-national differences in participation, academic influence and interactions in RG between Chinese and U.S. research universities as measured by RG metrics?

$R Q 2$. What are the characteristics of social networks formulated among users based on follower-followee relationships in RG, and how do they differ across the two countries?

This study contributes to a better understanding of cross-national differences in the scholarly use of academic social networking sites as researchers around the world are embracing such platforms for global reach and collaboration. This research could identify gaps and opportunities for universities and academics to maximize their scholarly impact on this global platform and promote effective and collaborative outreach practices to better connect with their peers world-wide. 


\section{Literature review}

\section{Academic social networking (ASN) sites and metrics}

ASN is specially designed for scholarly communication and usage. As an important channel for academic research sharing and informal communication, ASN sites offer responsiveness and informality that is not possible with the formal publishing process (Ovadia 2014) and an effective means for promoting research interaction and cooperation (Manca and Ranieri 2017).

ResearchGate (RG), launched in 2008, is becoming one of the most popular ASN sites (Li et al. 2018). According to RG's official data, more than 19 million scientists and professional researchers have signed in on the site (ResearchGate 2020). RG allows users to present their expertise, skills and recent projects for potential cooperation and facilitates collaboration and interaction among users (Abdulhayoglu and Thijs 2017). RG has served as the primary space for academics to create scholarly identities, promote academic influences, share research, make new connections, and collaborate with peers (Thelwall and Kousha 2015; Kim 2018).

RG's success has driven related research on RG metrics, which has examined their effectiveness and compared these metrics with other academic rankings (Thelwall and Kousha 2015; Yu et al. 2016; Orduna-Malea et al. 2017). These studies not only showed the high correlation between RG metrics and most of the widely adopted metrics, such as those in Web of Science (Thelwall and Kousha 2015), Mendeley, and Google Scholar citations (Martín-Martín et al. 2016), but also suggested that metrics from RG, along with other bibliometrics, can be used to measure researchers' and institutions' academic performance in a more holistic way (Yu et al. 2016). Among the variety of RG metrics, RG score, which measures researcher publications, questions asked and answered, and the number of followers, shows potential to be an effective indicator for measuring both institutional and individual performance (Yan and Zhang 2018).

\section{Scholarly use of ASN and cross-national differences}

Previous research on ASN has focused on the motivations for using ASN sites. With the benefits of publication sharing and peer networking functions, users have mainly used ASN sites for uploading and sharing research outputs, interacting with colleagues and peers, acquiring knowledge and techniques, presenting their works to a broader audience, as well as gaining self-improvement and promotion (Meishar-Tal and Pieterse 2017; Okeji et al. 2019).

For the most part, cross-national studies have focused on national and cultural differences in user behavior on general social networks like Facebook and Twitter (Karpinski et al. 2013; Yuan and Fussell 2017). Results suggest that national and cultural differences can significantly impact the motivations for using social networking sites (SNSs) and encourage different types of SNS usage (Vasalou et al. 2010; Lee et al. 2016). Existing cross-national studies have reported SNS usage differences between and within both Western (more individualistic) and Eastern (more collectivistic) countries such as America and China (Choi et al. 2011; Luo et al. 2014; Liu et al. 2016). 
Previous ASN studies have examined specific countries for case studies, such as the U.S., Turkey, South Africa, and Middle Eastern countries (Yan and Zhang 2018; Onyancha 2015; Bardakci et al. 2018; Shehata 2019). These studies have seldom compared differences in using ASN sites from the perspective of national differences, especially, those between developed and developing countries aiming to reach the global academic research communities. The influential role and wider reach of ASN sites used worldwide has drawn users from Eastern countries with non-native English language for wider scholarly communication and building international academic influence (Choi et al. 2013; Li and Chen 2014; Yuan and Fussell 2017). However, there are a limited number of validated measurements for cross-national comparisons of scholarly use of ASN sites, especially with non-Western user samples (Lee et al. 2016).

\section{Methodology \\ Sample}

In order to conduct the cross-national comparison between the U.S. and China, this study first chose the user sample from representative universities of both countries. Considering the member size and presence in RG, top Chinese research universities were selected for examination and comparison, as these institutions emphasize academic communication and have more international academic publications. On the other hand, U.S. research universities in different research activity levels were chosen for a detailed examination and comparison of RG use. Such a sampling approach could also support a comparison between the Chinese top universities and their U.S. counterparts.

Different research activity levels of the U.S. university sample were distinguished according to the Carnegie Classification of Institutions of Higher Education (Wikipedia 2016). The classification system lists three levels of doctoral universities: R1 (highest research activity), R2 (higher research activity), and R3 (moderate research activity). After parsing the universities based on this criterion, the top 20 universities at each level were selected according to National Universities Rankings (U.S. News 2016), as there are no rankings in the Carnegie Classification. Meanwhile, considering the RG members size, only top Chinese universities were chosen as counterparts. The top Chinese universities were selected based on a combination of top 20 universities from Wu Shu-lian Chinese University Research Ranking (Tencent Education 2016) and Chinese First-Class University Ranking (NSEAC 2016). As a result, 61 U.S. universities (21 for R1, 20 for R2, and 20 for R3) and 21 Chinese universities were selected as the sample, including the case of ties.

\section{Data source and RG metrics}

ResearchGate allows its users to create an academic profile, upload publications, follow other users, view others' profiles and publications, as well as answer and ask questions (Pérez-Rosés and Sebé 2015). Based on the user activities on the platform, RG provides a series of indicators, called RG metrics, on user profile pages, which provide insight on topics such as publications, reads, citations, profile views, followers, skills, and expertise to show the user's characteristics and academic impact. In addition, 
an RG score is provided, which is based on the publications in a user's profile and how other researchers interact with the user's content on RG (Citrome 2015).

The cross-national comparison of these RG metrics could reveal differences in user participation, academic influence, and interactions. Specifically, the following measures were used for comparisons:

- Participation: Active RG users affiliated with the sample institutions to some extent indicate the scale of the user participation of the institution.

- Academic influence: RG metrics such as RG score, profile views, publications, reads, and citations are used for measuring academic influence as the result of other users' participation activities.

- Interactions. The followers and followees, both the count and resulting networks, are useful to examine the interaction relationships.

\section{Data gathering}

The URLs of user profiles from the members page of each university were first obtained, then the publicly available personal user data were crawled from the user profile page of each university member. The user data include publicly available user demographic data (name, university, department, degree, and expertise) and the RG metrics data (RG score, publications, reads, citations, profile views, following, and followers).

The initial crawl began on September 22 and was completed on October 2, 2016. The crawl obtained the RG profile data of 284,093 members from 82 universities. Since RG score is calculated based on the personal research profile and interactions with other researchers, a score below 0.01 can be regarded as an automatically generated score, or as an inactive "zombie" user (Yan and Zhang, 2018). Hence, this study filtered out any user whose RG score was below 0.01 , which means the remaining 136,910 (48.19\%) members were relatively active on RG. Table 1 shows the final sample of U.S. Universities and Chinese Universities. The specific data for each university can be found in Appendix A.

\begin{tabular}{|c|c|c|c|c|c|}
\hline \multicolumn{2}{|c|}{ Category } & ID & Total & $\begin{array}{c}\text { Num with RG } \\
\text { score } \geq 0.01\end{array}$ & $\begin{array}{c}\text { Mean of \# of users } \\
\text { (RG score } \geq 0.01 \text { ) }\end{array}$ \\
\hline \multicolumn{2}{|c|}{ China } & $\mathrm{C} 01-\mathrm{C} 21$ & 116,034 & 49,827 & $2,372.71$ \\
\hline \multirow{4}{*}{ U.S. } & All & R101-R320 & 168,059 & 87,083 & $1,427.59$ \\
\hline & R1 & R101-R121 & 126,998 & 71,821 & $3,420.05$ \\
\hline & R2 & R201-R220 & 27,364 & 11,304 & 565.20 \\
\hline & R3 & R301-R320 & 13,697 & 3,958 & 197.90 \\
\hline
\end{tabular}

Table 1: Final sample of RG users in Chinese and U.S. research universities

In order to additionally examine the institutional follower-followee relationships among Chinese and U.S. universities, the crawler first obtained the followers' and followees' data from the personal profile page of every user in the sample. Due to limitations in presenting connectivity data on user profile pages in RG, the followers' and followees' data were limited to what was included in each user's main profile page. 
Specifically, for every user in the sample, the institution data of their top 10 followers and top 10 followees were collected. This second crawl took place from October 21 to November 15, 2016 and obtained data for 459,763 followers and 360,250 followees.

\section{Data analyses}

Descriptive statistical analyses of the RG metrics and between group nonparametric tests using SPSS 22.0 were conducted to compare the U.S. and Chinese universities. Since the non-parametric technique is a distribution-free test, the MannWhitney $\mathrm{U}$ test and Kruskal-Wallis $\mathrm{H}$ test are commonly used to measure the differences between two groups and between multiple groups, respectively (Pallant 2005; StatisticsSolutions 2017).

A social network analysis was conducted to identify and examine the social networks formulated based on follower-followee relationships among users affiliated with the sample Chinese and U.S. universities. Since the data of this study revealed that the within-institution self-follow relationships account for the majority of followerfollowee relationships in the sample, this study excluded these relationships to better compare the follower-followee relationships between institutions. As a result, 4,624 follower-followee relationships (directed edges) with total weight of 106,065 were obtained among the 82 institutions (nodes). This study then utilized Gephi 0.9.1 to perform the social network analysis and visualize the cross-country follower-followee relationships.

\section{Results}

\section{Comparison of RG metrics}

As shown in Table 2, there are distinct gaps between Chinese and U.S. universities in the number of citations per publication (China $=8.41$, U.S. $=15.45$ ) and profile views (China $=151.73$, U.S. $=203.01$ ). Nearly all of the mean values of the other metrics for top Chinese universities are behind the average level of U.S. universities, with the exception of number of followees (China $=25.82$, U.S. $=21.63$ ).

The RG metrics of Chinese universities are close to those of R2 universities in RG score and publications and R3 universities in citations per publication, profile views, and followers, but far behind R1 universities in most measures. However, Chinese universities have the highest number of followees (25.82) and the lowest reads per publication (32.81).

\begin{tabular}{lllll}
\hline RG Metrics & Category & Median & Mean & SD \\
& & & & \\
\hline RG score (per user) & China & 14.49 & 14.58 & 1.27 \\
\cline { 2 - 4 } & U.S. & 14.90 & 14.80 & 3.05 \\
\cline { 2 - 4 } & R1 & 17.97 & 17.95 & 1.26 \\
\cline { 2 - 4 } & R2 & 14.28 & 14.57 & 1.55 \\
\cline { 2 - 4 } & R3 & 11.71 & 11.72 & 2.08 \\
\hline Publications & China & 25.22 & 24.89 & 2.93 \\
\cline { 2 - 4 } (per user) & U.S. & 31.18 & 29.14 & 9.34 \\
\cline { 2 - 5 } & & & &
\end{tabular}




\begin{tabular}{|c|c|c|c|c|}
\hline & R1 & 37.26 & 37.67 & 5.16 \\
\hline & $\mathrm{R} 2$ & 30.50 & 29.86 & 4.77 \\
\hline & R3 & 18.93 & 19.47 & 6.76 \\
\hline \multirow[t]{5}{*}{ Reads/Publications } & China & 31.74 & 32.81 & 5.07 \\
\hline & U.S. & 38.07 & 39.96 & 11.67 \\
\hline & R1 & 37.27 & 37.58 & 3.96 \\
\hline & $\mathrm{R} 2$ & 38.64 & 40.15 & 6.61 \\
\hline & R3 & 39.04 & 42.27 & 18.92 \\
\hline \multirow[t]{5}{*}{ Citations/Publications } & China & 8.07 & 8.41 & 1.84 \\
\hline & U.S. & 14.26 & 15.45 & 4.46 \\
\hline & $\mathrm{R} 1$ & 19.31 & 19.90 & 2.88 \\
\hline & $\mathrm{R} 2$ & 12.70 & 13.69 & 3.50 \\
\hline & R3 & 12.68 & 12.53 & 2.77 \\
\hline \multirow{5}{*}{$\begin{array}{l}\text { Profile views } \\
\text { (per user) }\end{array}$} & China & 150.50 & 151.73 & 20.98 \\
\hline & U.S. & 208.86 & 203.01 & 55.44 \\
\hline & $\mathrm{R} 1$ & 238.55 & 246.43 & 35.85 \\
\hline & $\mathrm{R} 2$ & 197.36 & 205.93 & 36.13 \\
\hline & R3 & 139.72 & 154.50 & 49.78 \\
\hline \multirow{5}{*}{$\begin{array}{l}\text { Followers } \\
\text { (per user) }\end{array}$} & China & 28.41 & 28.88 & 2.64 \\
\hline & U.S. & 32.35 & 31.71 & 5.88 \\
\hline & $\mathrm{R} 1$ & 33.81 & 34.72 & 4.00 \\
\hline & $\mathrm{R} 2$ & 32.80 & 32.48 & 2.50 \\
\hline & R3 & 28.09 & 27.78 & 7.69 \\
\hline \multirow{5}{*}{$\begin{array}{l}\text { Followees } \\
\text { (per user) }\end{array}$} & China & 25.87 & 25.82 & 2.64 \\
\hline & U.S. & 22.00 & 21.63 & 3.60 \\
\hline & $\mathrm{R} 1$ & 21.84 & 21.73 & 1.67 \\
\hline & $\mathrm{R} 2$ & 22.80 & 22.45 & 2.22 \\
\hline & R3 & 19.77 & 20.70 & 5.62 \\
\hline
\end{tabular}

Table 2: RG metrics of universities by country and research activity level

Table 3 shows the between-group differences. Results from the Mann-Whitney $\mathrm{U}$ test indicate that the difference between Chinese and U.S. university RG scores (W = $672.000, p=0.738>0.05$ ) was not significant, while significant differences were found on all other RG metrics with p-values under 0.05 . In addition, Table 3 presents the comparison results between Chinese universities and different research activity levels of U.S. universities using the Kruskal-Wallis $\mathrm{H}$ test. Significant differences were found on all RG metrics with $\mathrm{p}$-values under 0.01 .

\begin{tabular}{llllll}
\hline \multirow{2}{*}{ RG metrics } & \multicolumn{2}{l}{$\begin{array}{l}\text { Mann-Whitney U test between } \\
\text { countries (China vs U.S.) }\end{array}$} & \multicolumn{3}{l}{$\begin{array}{l}\text { Kruskal-Wallis H test among } \\
\text { levels (China vs R1, R2, R3) }\end{array}$} \\
\cline { 2 - 6 } & $\mathbf{W}$ & Sig. (2-sided) & $\mathbf{X}^{\mathbf{2}}$ & $\mathbf{d f}$ & Sig. \\
\hline RG score (per user) & 672.000 & .738 & 55.820 & 3 & $.000^{* * *}$ \\
Publications (per user) & 876.000 & $.012^{*}$ & 56.218 & 3 & $.000^{* * *}$ \\
Reads/Publications & 895.000 & $.007^{* *}$ & 12.505 & 3 & $.006^{* *}$ \\
Citations/Publications & $1,220.000$ & $.000^{* * *}$ & 63.117 & 3 & $.000^{* * *}$ \\
Profile views (per user) & $1,015.000$ & $.000^{* * *}$ & 46.425 & 3 & $.000^{* * *}$ \\
Followers (per user) & 940.000 & $.001^{* *}$ & 26.920 & 3 & $.000^{* * *}$ \\
Followees (per user) & 181.000 & $.000^{* * *}$ & 25.475 & 3 & $.000^{* * *}$ \\
\hline
\end{tabular}

Table 3: The Mann-Whitney $\mathrm{U}$ test and Kruskal-Wallis $\mathrm{H}$ test on RG metrics 


\section{Comparison of social networks}

Table 4 shows the details of follower-followee relationships between Chinese and U.S. institutions. Universities in both China and the U.S. primarily follow their own countries' universities, as the within-group ratios of $63.32 \%$ (China) and $89.75 \%$ (U.S.) indicate. However, the between-group ratio shows U.S. universities as major targets for cross-country following relations (12.62\%) compared to the opposite direction (6.72\%). More specifically, users from Chinese universities almost exclusively follow users of R1 universities in the U.S. (32.89\%) rather than R2 (3.15\%) and R3 $(0.64 \%)$ universities. For U.S. universities, a decrease can be found in the within-group ratio of U.S. followees to their Chinese counterparts from R1 $(10.50 \%)$ to R3 (7.51\%). In addition, results show a dramatic decrease with the degradation of research activity level for each category of R1 (from $80.30 \%$ of R1 to $1.68 \%$ of R3), R2 (from $72.38 \%$ of R1 to $4.39 \%$ of R3) and R3 (from $67.28 \%$ of R1 to $7.64 \%$ of R3). However, the gaps do grow smaller from category R1 to R3.

\begin{tabular}{|c|c|c|c|c|}
\hline \multicolumn{2}{|c|}{ Category } & \multirow{2}{*}{$\begin{array}{l}\text { Weight } \\
23,104\end{array}$} & \multirow{2}{*}{$\begin{array}{l}\text { Within-group } \\
\text { ratio }\end{array}$} & \multirow{2}{*}{$\begin{array}{l}\text { Between-group } \\
\text { ratio } \\
21.78 \% \\
\end{array}$} \\
\hline China & $\begin{array}{l}\text { China } \rightarrow \\
\text { China }\end{array}$ & & & \\
\hline & China $\rightarrow$ U.S. & 13,383 & $36.68 \%$ & $12.62 \%$ \\
\hline & China $\rightarrow$ R1 & 11,999 & $32.89 \%$ & $11.31 \%$ \\
\hline & China $\rightarrow$ R2 & 1,150 & $3.15 \%$ & $1.08 \%$ \\
\hline & China $\rightarrow$ R3 & 234 & $0.64 \%$ & $0.22 \%$ \\
\hline \multirow[t]{14}{*}{ U.S. } & U.S. $\rightarrow$ U.S. & 62,446 & $89.75 \%$ & $58.88 \%$ \\
\hline & U.S. $\rightarrow$ China & 7,132 & $10.25 \%$ & $6.72 \%$ \\
\hline & R1 $\rightarrow$ China & 6,267 & $10.50 \%$ & $5.91 \%$ \\
\hline & $\mathrm{R} 1 \rightarrow \mathrm{R} 1$ & 47,910 & $80.30 \%$ & $45.17 \%$ \\
\hline & $\mathrm{R} 1 \rightarrow \mathrm{R} 2$ & 4,488 & $7.52 \%$ & $4.23 \%$ \\
\hline & $\mathrm{R} 1 \rightarrow \mathrm{R} 3$ & 1,001 & $1.68 \%$ & $0.94 \%$ \\
\hline & R2 $\rightarrow$ China & 689 & $9.10 \%$ & $0.65 \%$ \\
\hline & $\mathrm{R} 2 \rightarrow \mathrm{R} 1$ & 5,478 & $72.38 \%$ & $5.16 \%$ \\
\hline & $\mathrm{R} 2 \rightarrow \mathrm{R} 2$ & 1,069 & $14.13 \%$ & $1.01 \%$ \\
\hline & $\mathrm{R} 2 \rightarrow \mathrm{R} 3$ & 332 & $4.39 \%$ & $0.31 \%$ \\
\hline & R3 $\rightarrow$ China & 176 & $7.51 \%$ & $0.17 \%$ \\
\hline & $\mathrm{R} 3 \rightarrow \mathrm{R} 1$ & 1,577 & $67.28 \%$ & $1.49 \%$ \\
\hline & $\mathrm{R} 3 \rightarrow \mathrm{R} 2$ & 412 & $17.58 \%$ & $0.39 \%$ \\
\hline & $\mathrm{R} 3 \rightarrow \mathrm{R} 3$ & 179 & $7.64 \%$ & $0.17 \%$ \\
\hline
\end{tabular}

Table 4: Follower-followee relationship summaries between Chinese and U.S. universities

For a visual display and interpretation of the social network structure of the universities, the force-directed "ForceAtlas2" layout was implemented to turn structural proximities into visual proximities (Jacomy et al. 2014). As shown in Figure 1, the overall social network was made with nodes (sample universities) and directed edges (follower-followee connections). The node size is determined by the weighted degree 
(the sum of the weighted in-degree and out-degree) and reflects the frequency at which an institution makes and receives connections with other institutions. The direction of an edge indicates following, and its thickness reflects the frequency of follower-followee occurrences.

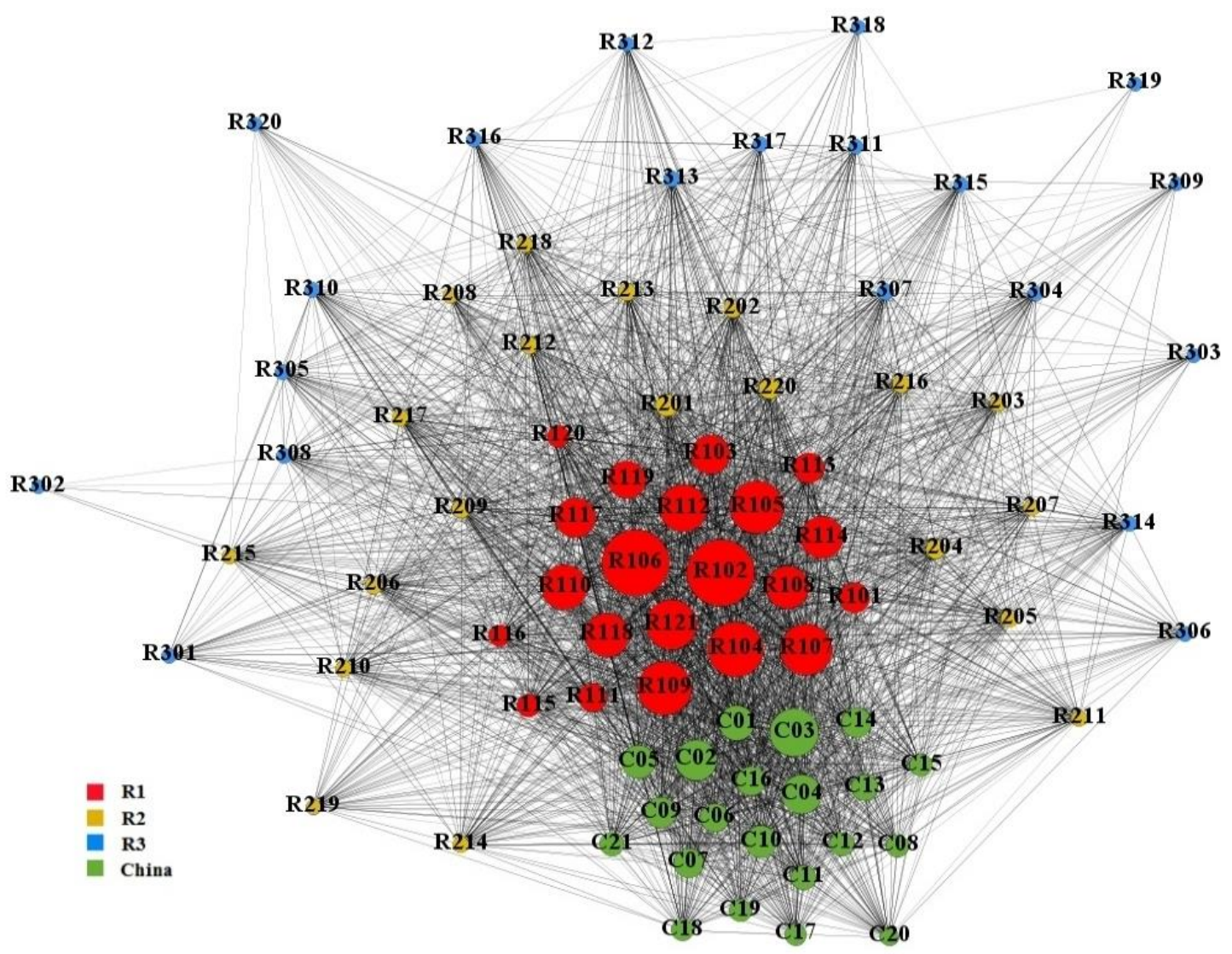

Figure 1: The follower-followee social network of Chinese and U.S. universities

The figure reveals that the weighted degrees of R3 universities are much fewer in number than those of R1, R2, and Chinese universities. "Stanford University (R106)" (11,190 weighted degree) and "Harvard University (R102)" (11,160 weighted degree) are the two largest nodes. "University of Pennsylvania (R109)" has the highest betweenness centrality (115.80) and closeness centrality (0.96). These measures suggest high reachability and variety in a member's network (Leydesdorff 2007; Hoffmann et al. 2016); thus, "University of Pennsylvania (R109)" is in a key position on the shortest path of the connections among most universities.

While U.S. universities are mainly distributed in three layers, R1 universities are closely linked together in the center of the social network. The connections appear much denser as the research activity level of the institutions intensifies. Figure 1 also shows that, within-country following aside, the top Chinese universities are closely connected with R1 universities.

Table 5 summarizes the institutional social network properties of universities. R1 universities appear fully self-connected, but the connections dramatically decrease with decreasing research activity level. This is supported by the decreasing of density (from 
1.000 of R1 to 0.216 of R3), average degree (from 40.000 of R1 to 8.200 of R3), and average weighted degree (from 2281.429 of R1 to 8.950 of R3), as well as the increasing of average path length (from 1.000 of R1 to 1.892 of R3) and diameter (from 1 of R1 to 4 of R3). There is a dramatic drop of average clustering coefficient with decreasing research activity level as well (from 1.000 of R1 to 0.379 of R3), which explains why the R1 universities are centralized and the R3 universities are far more widely distributed. The social network properties of Chinese universities are much closer to those of R1 universities, which show a similar, fully self-connected and concentrated research activity level.

\begin{tabular}{lllllllll}
\hline Category & $\begin{array}{l}\text { Nodes } \\
\text { No. }\end{array}$ & $\begin{array}{l}\text { Nodes } \\
\text { ratio }\end{array}$ & Density & $\begin{array}{l}\text { Average } \\
\text { degree }\end{array}$ & $\begin{array}{l}\text { Average } \\
\text { weighted } \\
\text { degree }\end{array}$ & Diameter & $\begin{array}{l}\text { Average } \\
\text { clustering } \\
\text { coefficient }\end{array}$ & $\begin{array}{l}\text { Average } \\
\text { Path } \\
\text { length }\end{array}$ \\
\hline China & 21 & $\begin{array}{l}25.61 \\
\%\end{array}$ & 0.995 & 39.810 & $1,100.190$ & 2 & 0.995 & 1.005 \\
U.S. & 61 & $\begin{array}{l}74.39 \\
\%\end{array}$ & 0.689 & 82.623 & $1,023.705$ & 3 & 0.825 & 1.313 \\
\hline R1 & 21 & $\begin{array}{l}25.61 \\
\%\end{array}$ & 1.000 & 40.000 & $2,281.429$ & 1 & 1.000 & 1.000 \\
R2 & 20 & $\begin{array}{l}24.39 \\
\%\end{array}$ & 0.755 & 28.700 & 53.450 & 2 & 0.768 & 1.245 \\
R3 & 20 & $\begin{array}{l}24.39 \\
\%\end{array}$ & 0.216 & 8.200 & 8.950 & 4 & 0.379 & 1.892 \\
\hline Overall & 82 & $100 \%$ & 0.696 & 112.780 & $1,293.476$ & 3 & 0.823 & 1.305 \\
\hline
\end{tabular}

Table 5: Social network properties of universities by country and research activity level

\section{Discussion}

This study conducted an analysis of user participation, interactions, and academic influences using RG metrics from a sample of research universities in the U.S. and China to examine the differences between them. The major findings of this study are highlighted and discussed around the research questions of this study.

\section{RG participation and metrics differences}

In general, the participation-based metrics of top Chinese universities are comparable to average U.S. research universities but behind compared to the most research-intense U.S. universities (R1). The relatively low uptake of RG in China could be attributed to international users primarily using native sites (Yuan and Fussell 2017), and a non-native ASN site like RG is only preferred for international academic interaction and representation of their English research outputs, which is only a portion of their research activities. These factors may result in a lack of sense of belonging for Chinese users and may attenuate their usage intention (Liu et al. 2018).

The significant differences in nearly all of the RG metrics found in this study suggest that cross-national differences between the U.S. and Chinese universities do exist on RG, extending previous findings that user behaviors on RG have institutional differences in South Africa (Onyancha 2015) and that ASN site use may help individuals reinforce existing norms and learn new cultural norms, which may further influence 
their cultural orientations as proven in other SNS sites (Li and Tsai 2015; Li and Liu 2017).

Results also show that RG scores associate positively with research activity level of universities, supporting previous findings that the RG score serves as an effective indicator of academic influence (Muscanell and Utz 2015; Nicholas et al. 2015). The average RG score of top Chinese universities was closely comparable to that of R2 U.S. universities, which offers empirical evidence and contributes to the ongoing discussion for China to embrace altmetrics or a similar, more balanced metrics system to add to the monopoly of the traditional metrics-based rewards systems (Da Silva 2017).

Regarding publication-related metrics, the average number of publications per user from Chinese universities appeared to be closest to those of R2 U.S. universities. Despite this, however, both the number of reads per publication and the number of citations per publication of Chinese universities remained at the lowest level. Because the average number of publications per user and of citations per publication increased with the university's research activity level, the findings suggest that the academic influence of Chinese universities is also limited. That RG is an English-language platform could be a barrier for active usage, especially for the older generation users who prefer to write and share academic publications in Chinese. It should be noted that the academic influence of Chinese RG users does not reflect the entire academic contribution of Chinese scholars, as Chinese publications are not present in RG. The interpretation of the academic influence should be put in the context of the global scholarly communication and impact. Moreover, the more dramatic gap in citations per publication over publications alone implies that international research from Chinese universities should place much more effort on the quality of publications rather than the quantity. Additionally, since international collaboration can help increase visibility of Chinese papers (Shu et al. 2018), encouraging RG use could help reduce the gap in academic influence between Chinese and U.S. universities.

This study shows that the average number of reads per publication is negatively associated with research level of universities. One reason for this could be that this metric is not directly associated with academic influence (Nicholas et al. 2016). Moreover, reads per publication could be unstable due to omissions of reads for publications published prior to the RG launch or to the copyright concerns of uploading full-text versions of formal publications on RG (Citrome 2015; Nicholas et al. 2015).

For the rest of the RG metrics, the number of profile views and followers of Chinese universities are close only to R3 U.S. universities, which highlights their comparatively low popularity on international ASN sites. On the other hand, the number of followees of Chinese universities is much higher than those of U.S. universities, which shows a more positive following behavior of Chinese university members.

Overall, the significant gaps of RG metrics among different research activity levels of universities supports that RG metrics could be effective in measuring research institutions. Meanwhile the comparison results of RG metrics reveal the gap between the two countries, especially in their academic influence. Such a gap may also be attributed to such factors as native language users from a Western, individualistic country being more capable of utilizing the international SNS as well as ASN sites for 
self-presentation (Ma et al. 2017), while the non-native language users from Eastern, collectivistic countries take efforts to obtain academic communication and expand academic relations, indicated by their more positive following behavior.

\section{Social characteristics}

The follower-followee relationships of users provides a specific perspective for social characteristic comparisons between U.S. and Chinese universities. Firstly, users from both countries mostly follow users from the same universities. This suggests that users from both countries interact primarily within their offline community, such as with institutional colleagues, thus creating an institutional homophily (Hoffmann et al. 2016). The findings also reveal a general trend of universities primarily following others from the same country. However, a trend of Chinese users following U.S. users still exists, and in much greater frequency than U.S. users following Chinese users. As previous research suggested, a home-country SNS is valuable to maintain networks, while an international one is important for creating connections with new friends (Yuan and Fussell 2017); our results show such notion in an ASN context.

Another major finding is that international interactions occur primarily among top universities in each country with a disproportionate ratio of Chinese followers to U.S. followers and the number of followees decreasing from R1 to R3. Top U.S. research activity level universities interact not only with peers within the U.S. but also with other countries. At the same time, these top research activity level universities are major following objects, supporting the idea that the main objectives of RG users are to stay current and view others' research (Nicholas et al. 2015; Elsayed 2016). In terms of international academic influence building, RG could be more valuable for Chinese universities compared to their native ASN platforms.

Higher research activity level universities were also found to have well-connected social networks. U.S. R1 universities were fully self-connected; however, Chinese universities were also nearly fully self-connected because of their positive following behavior. This finding suggests that interactions among top universities play a primary role among researchers in ASN regardless of the country. On the other hand, this study showed the interaction networks become loose with the degradation of research activity level of universities, suggesting that social networking and scanning are less active among users from universities at a lower research activity level.

\section{Limitations and future research}

This study is limited to RG, while many other such platforms are also available. There are certain platform-specific limitations, as such platforms do not include all research output, nor do they require users to add their nationality information. RG user data were obtained using the universities' member lists on RG, and the cross-national comparison was conducted according to the nationality of the users' affiliated universities instead of that of users. Future studies may investigate institutions in more countries for a better understanding of utilization of RG and other social networks in facilitating and enhancing scholarly productivity, communication, and assessment on a global scale. Furthermore, this study focused on cross-national comparisons and 
observed differences in user behaviors on RG. Future research may further examine the cultural aspects of such differences that affect the behaviors of using ANSs. As user participation and RG use may also be affected by other factors such as discipline, as suggested in other studies (e.g., Yan et al. 2021), future comparative ASN research could additionally explore and examine these disciplinary aspects.

\section{Conclusions}

The comparisons of participation, interactions, and academic influences using RG metrics of users affiliated with a sample of research universities in the U.S. and China revealed that in the ASN site RG, the participation of top Chinese universities and their overall performance as measured by RG score and publications are largely in line with U.S. research universities. However, the academic influence and popularity of top Chinese universities-as measured by citations per publication, profile views, and followers-are basically at the same level with those in moderate research activity level (R3) universities in the U.S. Obvious gaps between a non-native language, developing country (China) and native-language, developed one (U.S.) were found using RG. However, the number of followees is the highest-level metric for Chinese RG users, suggesting that Chinese RG users tend to follow their peers, both in China and in the U.S., to stay current. It is a positive sign and feasible way for users from developing countries to spread their reach in global scholarly communication and enhance their academic influence through ASN sites like RG.

The top research universities in both China and the U.S. have well-connected social networks; however, this study suggests that Chinese users follow U.S. users more than the other way around. This provides opportunities for international collaborations between universities with a high research activity level by expanding the existing oneway following relationship.

Finally, this study supports the notion that RG metrics can effectively serve as both institutional and national evaluation tools. Based on this study's results, the idea of embracing RG and other research-oriented academic social networking sites seem to be a good way to promote academic influence and encourage international collaborations.

\section{Acknowledgements}

This work is supported by the National Natural Science Foundation of China (No. 71904148).

\section{About the authors}

Weiwei Yan, Ph.D., is an Associate Professor in the School of Information Management at Wuhan University, China. His research interests include user information behavior and scientific collaboration. E-mail: yanww@whu.edu.cn.

Yin Zhang, Ph.D., is a Professor in the School of Information at Kent State University, United States. Her research and teaching areas include user information- 
seeking behavior, information uses and services, and scientometrics. E-mail:

yzhang4@kent.edu. Website: https://yinzhang.ischool.kent.edu/.

\section{References}

Abdulhayoglu, Mehmet, and Bart Thijs. 2017. "Use of ResearchGate and Google CSE for Author Name Disambiguation." Scientometrics 111 (3): 1965-85.

https://doi.org/10.1007/s11192-017-2341-y.

Bardakcl, Salih, Ömer Arslan, and Tuğba Kocadağ Ünver. 2018. "How Scholars Use Academic Social Networking Services." Information Development 34 (4): 334-45. https://doi.org/10.1177/0266666917712108.

Choi, Sejung Marina, Yoojung Kim, Yongjun Sung, and Dongyoung Sohn. 2011. "Bridging or Bonding? A Cross-Cultural Study of Social Relationships in Social Networking Sites." Information, Communication \& Society 14 (1): 107-29. https://doi.org/10.1080/13691181003792624.

Choi, Junho, Jaemin Jung, and Sang-Woo Lee. 2013. "What Causes Users to Switch from a Local to a Global Social Network Site? The Cultural, Social, Economic, and Motivational Factors of Facebook's Globalization." Computers in Human Behavior 29 (6): 2665-73. https://doi.org/10.1016/j.chb.2013.07.006.

Citrome, Leslie. 2015. "My Two Favourite Professional Social Networking Sites: LinkedIn and ResearchGate - How They Can Help You, or Hurt You." International Journal of Clinical Practice 69 (6): 623-624. https://doi.org/10.1111/ijcp.12681.

Da Silva, Jaime Teixeira. 2017. "Does China Need to Rethink Its Metrics- and Citation-Based Research Rewards Policies?" Scientometrics 112 (3): 1853-57. https://doi.org/10.1007/s11192-017-2430-y.

Elsayed, Amany M. 2016. "The Use of Academic Social Networks among Arab Researchers: A Survey." Social Science Computer Review 34 (3): 378-91. https://doi.org/10.1177/0894439315589146.

Hoffmann, Christian Pieter, Christoph Lutz, and Miriam Meckel. 2016. "A Relational Altmetric? Network Centrality on ResearchGate as an Indicator of Scientific Impact. Journal of the Association for Information Science and Technology 67 (4): 765775. https://doi.org/10.1002/asi.23423.

Jacomy, Mathieu, Tommaso Venturini, Sebastien Heymann, and Mathieu Bastian. 2014. "ForceAtlas2, a Continuous Graph Layout Algorithm for Handy Network Visualization Designed for the Gephi Software." PloS One 9 (6): e98679. https://doi.org/10.1371/journal.pone.0098679.

Karpinski, Aryn C., Paul A. Kirschner, Ipek Ozer, Jennifer A. Mellott, and Pius Ochwo. 2013. "An Exploration of Social Networking Site Use, Multitasking, and Academic Performance among United States and European University Students." Computers in Human Behavior 29 (3): 1182-92. https://doi.org/10.1016/j.chb.2012.10.011.

Kim, Youngseek. 2018. "An Empirical Study of Biological Scientists' Article Sharing through ResearchGate." Aslib Journal of Information Management 70 (5): 458-80. https://doi.org/10.1108/AJIM-05-2018-0126. 
Lee, Soon Li, Jung-Ae Kim, Karen Jennifer Golden, Jae-Hwi Kim, and Miriam Sang-Ah Park. 2016. "A Cross-Cultural Examination of SNS Usage Intensity and Managing Interpersonal Relationships Online: The Role of Culture and the Autonomous-Related Self-Construal." Frontiers in Psychology 7 (April).

https://doi.org/10.3389/fpsyg.2016.00376.

Lee, Jongwook, Sanghee Oh, Hang Dong, Fang Wang, and Gary Burnett. 2019.

"Motivations for Self-archiving on an Academic Social Networking Site: A Study on Researchgate." Journal of the Association for Information Science \& Technology 70 (6): 563-74. https://doi.org/10.1002/asi.24138.

Leydesdorff, Loet. 2007. "Betweenness Centrality as an Indicator of the Interdisciplinarity of Scientific Journals." Journal of the American Society for Information Science \& Technology 58 (9): 1303-19. https://doi.org/10.1002/asi.20614.

Li, Cong, and Jiangmeng Liu. 2017. "Effects of Using Social Networking Sites in Different Languages: Does Spanish or English Make a Difference?" Computers in Human Behavior 74 (September): 257-64. https://doi.org/10.1016/j.chb.2017.04.031.

Li, Cong, and Wan-Hsiu Sunny Tsai. 2015. "Social Media Usage and Acculturation: A Test with Hispanics in the US." Computers in Human Behavior 45 (April): 204-12. https://doi.org/10.1016/j.chb.2014.12.018.

Li, Lei, Daqing He, Chengzhi Zhang, Li Geng, and Ke Zhang. 2018. "Characterizing PeerJudged Answer Quality on Academic Q\&A Sites." Aslib Journal of Information Management 70 (3): 269-87. https://doi.org/10.1108/AJIM-11-2017-0246. Li, Xiaoqian, and Wenhong Chen. 2014. "Facebook or Renren? A Comparative Study of Social Networking Site Use and Social Capital among Chinese International Students in the United States." Computers in Human Behavior 35: 116-123. https://doi.org/10.1016/j.chb.2014.02.012.

Liu, Dong, Sarah E. Ainsworth, and Roy F. Baumeister. 2016. "A Meta-Analysis of Social Networking Online and Social Capital." Review of General Psychology 20 (4): 36991. https://doi.org/10.1037/gpr0000091.

Liu, Qian, Zhen Shao, and Weiguo Fan. 2018. "The Impact of Users' Sense of Belonging on Social Media Habit Formation: Empirical Evidence from Social Networking and Microblogging Websites in China." International Journal of Information Management 43 (December): 209-23. https://doi.org/10.1016/j.ijinfomgt.2018.08.005.

Luo, Chuan, Jing Wu, Yani Shi, and Yun Xu. 2014. "The Effects of Individualismcollectivism Cultural Orientation on EWOM Information." International Journal of Information Management 34 (4): 446-56. https://doi.org/10.1016/j.ijinfomgt.2014.04.001.

Ma, Jenny Weichen, Yusheng Yang, and Jonathan A.J. Wilson. 2017. "A Window to the Ideal Self: A Study of UK Twitter and Chinese Sina Weibo Selfie-Takers and the Implications for Marketers." Journal of Business Research 74 (May): 139-42. https://doi.org/10.1016/j.jbusres.2016.10.025.

Manca, Stefania, and Maria Ranier. 2017. "Networked Scholarship and Motivations for Social Media Use in Scholarly Communication." International Review of Research in 
Open and Distributed Learning 18 (2): 123-38.

https://doi.org/10.19173/irrodl.v18i2.2859.

Martín-Martín, Alberto, Enrique Orduna-Malea, Juan Ayllón, and Emilio Delgado López-

Cózar. 2016. "The Counting House: Measuring Those Who Count. Presence of

Bibliometrics, Scientometrics, Informetrics, Webometrics and Altmetrics in the Google Scholar Citations, ResearcherID, ResearchGate, Mendeley \& Twitter."

Accessed June 16, 2019. https://arxiv.org/ftp/arxiv/papers/1602/1602.02412.pdf.

Meishar-Tal, Hagit, and Efrat Pieterse. 2017. "Why Do Academics Use Academic Social

Networking Sites?" International Review of Research in Open and Distributed

Learning 18 (1): 1-22. https://doi.org/10.19173/irrodl.v18i1.2643.

Muscanell, Nicole, and Sonja Utz. 2015. "Academics' Use of ResearchGate." Accessed

June 16, 2019. http://www.open-science-conference.eu/wp-

content/uploads/2015/04/13.05_Poster_-_Academics_Use_of_ResearchGate.pdf.

Network of Science and Education Evaluation in China (NSEAC). 2016. "Chinese First-

Class University Ranking 2016." Accessed June 16, 2019.

http://www.nseac.com/html/14/675876.html.

Nicholas, David, David Clark, and Eti Herman. 2016. "ResearchGate: Reputation

Uncovered." Learned Publishing 29 (3): 173-82.

https://doi.org/10.1002/leap.1035.

Nicholas, David, Eti Herman, Hamid Jamali, Blanca Rodríguez- Bravo, Cherifa

Boukacem-Zeghmouri, Tom Dobrowolski, and Stephanie Pouchot. 2015. "New

Ways of Building, Showcasing, and Measuring Scholarly Reputation." Learned

Publishing 28 (3): 169-83. https://doi.org/10.1087/20150303.

Okeji, Clement Chukwuma, Monica Eberechukwu Eze, and Nneka Maureen Chibueze. 2019.

"Awareness and Use of Self-Archiving Options Among Academic Librarians in Nigerian

Universities." Global Knowledge, Memory and Communication 68 (1/2): 2-16.

https://doi.org/10.1108/GKMC-12-2017-0109.

Onyancha, Omwoyo Bosire. 2015. "Social Media and Research: An Assessment of the

Coverage of South African Universities in ResearchGate, Web of Science and the

Webometrics Ranking of World Universities." South African Journal of Libraries \&

Information Science 81 (1): 8-20. https://doi.org/10.7553/81-1-1540.

Orduna-Malea, Enrique, Alberto Martín-Martín, Mike Thelwall, and Emilio Delgado López-

Cózar. 2017. "Do ResearchGate Scores Create Ghost Academic Reputations?"

Scientometrics 112 (1): 443-60. https://doi.org/10.1007/s11192-017-2396-9.

Ovadia, Steven. 2014. "ResearchGate and Academia.Edu: Academic Social Networks."

Behavioral \& Social Sciences Librarian 33 (3): 165-69.

https://doi.org/10.1080/01639269.2014.934093.

Pallant, Julie. 2005. SPSS Survival Manual: A Step by Step Guide to Using SPSS for

Windows (Version 12). New South Wales, Australia: Allen \& Unwin.

Pérez-Rosés, Herbert, and Fransec Sebé. 2015. "Synthetic Generation of Social Network

Data with Endorsements." Journal of Simulation 9 (4): 279-286.

https://doi.org/10.1057/jos.2014.29.

ResearchGate. 2020. "About." Accessed December 16, 2020.

https://www.researchgate.net/about. 
Shehata, Ahmed Maher Khafaga. 2019. "Exploring the Scholarly Communication Styles of Arab Social Science and Humanities Scholars." Learned Publishing 32 (4): 304-11. https://onlinelibrary.wiley.com/doi/epdf/10.1002/leap.1253.

Shu, Fei, Wen Lou, and Stefanie Haustein. 2018. "Can Twitter Increase the Visibility of Chinese Publications?" Scientometrics 116 (1): 505-19.

https://doi.org/10.1007/s11192-018-2732-8.

StatisticsSolutions. 2017. "Non-Parametric Analysis." Accessed June 16, 2019. http://www.statisticssolutions.com/non-parametric-analysis/.

Tencent Education. 2016. "Wu Shu-lian Chinese University Research Ranking 2016." Accessed June 16, 2019. http://edu.qq.com/a/20160406/026305.htm.

Thelwall, Mike, and Kayvan Kousha. 2015. "Research Gate: Disseminating, Communicating, and Measuring Scholarship?" Journal of the Association for Information Science \& Technology 66 (5): 876-89. https://doi.org/10.1002/asi.23236.

U.S. News. 2016. "National Universities Rankings." Accessed June 16, 2019. http://colleges.usnews.rankingsandreviews.com/best-colleges/rankings/nationaluniversities.

Vasalou, Asimina, Adam N. Joinson, and Delphine Courvoisier. 2010. "Cultural Differences, Experience with Social Networks and the Nature of 'True Commitment' in Facebook." International Journal of Human-Computer Studies 68 (10): 719-28. https://doi.org/10.1016/j.ijhcs.2010.06.002.

Wikipedia. 2016. "List of Research Universities in the United States." Accessed June 16, 2019.

https://en.wikipedia.org/wiki/List_of_research_universities_in_the_United_States.

Xia, Feng, Xiaoyan Su, Wei Wang, Chenxi Zhang, Zhaolong Ning, and Iva Lee. 2016. "Bibliographic Analysis of Nature Based on Twitter and Facebook Altmetrics Data." PLOS ONE, 11 (12): 1-14. https://doi.org/10.1371/journal.pone.0165997.

Yan, Weiwei, and Yin Zhang. 2018. "Research Universities on the ResearchGate Social Networking Site: An Examination of Institutional Differences, Research Activity Level, and Social Networks Formed." Journal of Informetrics 12 (1): 385-400. https://doi.org/10.1016/j.joi.2017.08.002.

Yan, Weiwei, Yin Zhang, Tao Hu, and Sonali Kudva. 2021. "How does scholarly use of academic social networking sites differ by academic discipline? A case study using ResearchGate." Information Processing and Management 58 (1): 102430. https://doi.org/10.1016/j.ipm.2020.102430.

Yu, Min-Chun, Yen-Chun Jim Wu, Wadee Alhalabi, Hao-Yun Kao, and Wen-Hsiung Wu. 2016. "ResearchGate: An Effective Altmetric Indicator for Active Researchers?" Computers in Human Behavior 55, Part B (February): 1001-1006. https://doi.org/10.1016/j.chb.2015.11.007.

Yuan, Chien Wen (Tina), and Susan R. Fussell. 2017. "A Tale of Two Sites: Dual Social Network Site Use and Social Network Development." Computers in Human Behavior 74 (September): 83-91. https://doi.org/10.1016/j.chb.2017.04.011. 


\begin{tabular}{|c|c|c|c|c|c|}
\hline Category & ID & Universities & Total num & $\begin{array}{l}\text { Num }(\mathbf{R G} \\
\text { score } \geq \mathbf{0 . 0 1})\end{array}$ & $\begin{array}{l}\text { Ratio }(\mathbf{R G} \\
\text { score } \geq \mathbf{0 . 0 1})\end{array}$ \\
\hline \multirow[t]{21}{*}{ China } & $\mathrm{C} 01$ & Zhejiang University & 9,510 & 4,011 & $42.18 \%$ \\
\hline & $\mathrm{C} 02$ & Peking University & 9,616 & 3,601 & $37.45 \%$ \\
\hline & $\mathrm{C} 03$ & Tsinghua University & 11,792 & 5,023 & $42.60 \%$ \\
\hline & $\mathrm{C} 04$ & Shanghai Jiao Tong University & 10,179 & 4,054 & $39.83 \%$ \\
\hline & $\mathrm{C} 05$ & Fudan University & 7,409 & 3,167 & $42.75 \%$ \\
\hline & $\mathrm{C} 06$ & Nanjing University & 4,354 & 1,983 & $45.54 \%$ \\
\hline & $\mathrm{C} 07$ & Wuhan University & 6,307 & 2,519 & $39.94 \%$ \\
\hline & $\mathrm{C} 08$ & Sichuan University & 2,744 & 1,479 & $53.90 \%$ \\
\hline & $\mathrm{C} 09$ & Sun Yat-Sen University & 5,611 & 2,459 & $43.82 \%$ \\
\hline & $\mathrm{C} 10$ & Huazhong University of Science and Technology & 6,464 & 2,837 & $43.89 \%$ \\
\hline & $\mathrm{C} 11$ & Shandong University & 2,722 & 1,691 & $62.12 \%$ \\
\hline & $\mathrm{C} 12$ & Jilin University & 4,661 & 2,006 & $43.04 \%$ \\
\hline & $\mathrm{C} 13$ & Harbin Institute of Technology & 3,887 & 2,108 & $54.23 \%$ \\
\hline & $\mathrm{C} 14$ & University of Science and Technology of China & 6,308 & 2,738 & $43.41 \%$ \\
\hline & $\mathrm{C} 15$ & Nankai University & 2,888 & 1,207 & $41.79 \%$ \\
\hline & $\mathrm{C} 16$ & Xi'an Jiaotong University & 6,206 & 2,819 & $45.42 \%$ \\
\hline & $\mathrm{C} 17$ & Southeast University (China) & 3,116 & 1,204 & $38.64 \%$ \\
\hline & $\mathrm{C} 18$ & Central South University & 3,403 & 1,592 & $46.78 \%$ \\
\hline & C19 & South China University of Technology & 2,937 & 1,334 & $45.42 \%$ \\
\hline & $\mathrm{C} 20$ & Renmin University of China & 2,277 & 475 & $20.86 \%$ \\
\hline & $\mathrm{C} 21$ & Beijing Normal University & 3,643 & 1,520 & $41.72 \%$ \\
\hline U.S. & R101 & Princeton University & 3,057 & 1,644 & $53.78 \%$ \\
\hline \multirow[t]{20}{*}{$\mathrm{R} 1$} & R102 & Harvard University & 8,750 & 4,540 & $51.89 \%$ \\
\hline & R103 & University of Chicago & 5,059 & 2,615 & $51.69 \%$ \\
\hline & R104 & Yale University & 6,785 & 4,504 & $66.38 \%$ \\
\hline & R105 & Columbia University & 11,042 & 5,031 & $45.56 \%$ \\
\hline & R106 & Stanford University & 10,577 & 6,738 & $63.70 \%$ \\
\hline & R107 & MIT & 7,985 & 4,760 & $59.61 \%$ \\
\hline & R108 & Duke University & 5,622 & 3,199 & $56.90 \%$ \\
\hline & R109 & University of Pennsylvania & 8,734 & 5,160 & $59.08 \%$ \\
\hline & R110 & Johns Hopkins University & 6,319 & 3,342 & $52.89 \%$ \\
\hline & R111 & California Institute of Technology & 2,459 & 1,868 & $75.97 \%$ \\
\hline & R112 & Northwestern University & 6,811 & 4,113 & $60.39 \%$ \\
\hline & $\mathrm{R} 113$ & Brown University & 3,007 & 1,643 & $54.64 \%$ \\
\hline & R114 & Cornell University & 6,765 & 3,260 & $48.19 \%$ \\
\hline & $\mathrm{R} 115$ & Rice University & 2,167 & 1,163 & $53.67 \%$ \\
\hline & R116 & University of Notre Dame & 2,168 & 1,160 & $53.51 \%$ \\
\hline & $\mathrm{R} 117$ & Vanderbilt University & 5,690 & 3,831 & $67.33 \%$ \\
\hline & R118 & Washington University in St. Louis & 5,934 & 3,943 & $66.45 \%$ \\
\hline & R119 & Emory University & 5,089 & 3,339 & $65.61 \%$ \\
\hline & R120 & Georgetown University & 3,495 & 1,235 & $35.34 \%$ \\
\hline & R121 & University of California, Berkeley & 9,483 & 4,733 & $49.91 \%$ \\
\hline U.S. & R201 & Dartmouth College & 1,818 & 997 & $54.84 \%$ \\
\hline \multirow[t]{14}{*}{$\mathrm{R} 2$} & R202 & Wake Forest University & 893 & 391 & $43.78 \%$ \\
\hline & R203 & College of William and Mary & 1,112 & 350 & $31.47 \%$ \\
\hline & R204 & Rensselaer Polytechnic Institute & 1,608 & 778 & $48.38 \%$ \\
\hline & R205 & Lehigh University & 1,289 & 559 & $43.37 \%$ \\
\hline & R206 & Southern Methodist University & 1,182 & 444 & $37.56 \%$ \\
\hline & R207 & Worcester Polytechnic Institute & 1,056 & 412 & $39.02 \%$ \\
\hline & R208 & Yeshiva University & 585 & 204 & $34.87 \%$ \\
\hline & R209 & Brigham Young University-Provo & 2,110 & 1,151 & $54.55 \%$ \\
\hline & $\mathrm{R} 210$ & Baylor University & 1,341 & 527 & $39.30 \%$ \\
\hline & $\mathrm{R} 211$ & Stevens Institute of Technology & 1,176 & 417 & $35.46 \%$ \\
\hline & $\mathrm{R} 212$ & American University Washington DC & 1,600 & 412 & $25.75 \%$ \\
\hline & $\mathrm{R} 213$ & Miami University & 1,870 & 706 & $37.75 \%$ \\
\hline & $\mathrm{R} 214$ & Colorado School of Mines & 1,349 & 544 & $40.33 \%$ \\
\hline & $\mathrm{R} 215$ & Texas Christian University & 848 & 324 & $38.21 \%$ \\
\hline
\end{tabular}




\begin{tabular}{|c|c|c|c|c|c|}
\hline & $\mathrm{R} 216$ & Binghamton University-SUNY & 2,116 & 655 & $30.95 \%$ \\
\hline & $\mathrm{R} 217$ & Marquette University & 1,331 & 517 & $38.84 \%$ \\
\hline & R218 & University of Denver & 1,373 & 487 & $35.47 \%$ \\
\hline & $\mathrm{R} 219$ & University of Tulsa & 650 & 267 & $41.08 \%$ \\
\hline & $\mathrm{R} 220$ & University of Vermont & 2,057 & 1,162 & $56.49 \%$ \\
\hline U.S. & R301 & Pepperdine University & 680 & 129 & $18.97 \%$ \\
\hline \multirow[t]{19}{*}{ R3 } & R302 & Texas Wesleyan University & 190 & 17 & $8.95 \%$ \\
\hline & R303 & Fairleigh Dickinson University & 674 & 131 & $19.44 \%$ \\
\hline & R304 & Clark University & 698 & 198 & $28.37 \%$ \\
\hline & R305 & University of San Diego & 728 & 228 & $31.32 \%$ \\
\hline & R306 & SUNY College of Environmental Science and Forestry & 514 & 192 & $37.35 \%$ \\
\hline & R307 & Rochester Institute of Technology & 1,904 & 586 & $30.78 \%$ \\
\hline & R308 & University of San Francisco & 1,086 & 264 & $24.31 \%$ \\
\hline & R309 & Drew University & 255 & 58 & $22.75 \%$ \\
\hline & R310 & University of the Pacific (California -USA) & 586 & 219 & $37.37 \%$ \\
\hline & R311 & Seton Hall University & 754 & 234 & $31.03 \%$ \\
\hline & R312 & University of St. Thomas & 656 & 172 & $26.22 \%$ \\
\hline & R313 & DePaul University & 1,081 & 400 & $37.00 \%$ \\
\hline & R314 & Clarkson University & 676 & 321 & $47.49 \%$ \\
\hline & R315 & Hofstra University & 774 & 242 & $31.27 \%$ \\
\hline & R316 & Mercer University & 758 & 215 & $28.36 \%$ \\
\hline & R317 & Adelphi University & 841 & 206 & $24.49 \%$ \\
\hline & R318 & St. John Fisher College & 232 & 73 & $31.47 \%$ \\
\hline & R319 & Immaculata University & 181 & 15 & $8.29 \%$ \\
\hline & R320 & University of La Verne & 429 & 58 & $13.52 \%$ \\
\hline
\end{tabular}

Appendix A: RG user sample of Chinese and U.S. research universities 